\title{
Health-related quality of life in a PD-First programme in South Africa
}

\author{
Bianca Davidson ${ }^{1,2}$, Waldo Welgemoed ${ }^{3}$ Erika Jones ${ }^{1,2}$, Zibya Barday ${ }^{1,2}, K^{2}$ athryn Manning ${ }^{4}$, Nicola Wearne ${ }^{1,2}$ \\ 'Kidney and Hypertension Research Unit, University of Cape Town, ²Department of Nephrology and Hypertension, Groote Schuur Hospital, \\ Cape Town, ${ }^{3}$ Department of Medicine, University of Cape Town, and ${ }^{4}$ Statistical Department, University of Cape Town, South Africa.
}

\section{ABSTRACT}

Groote Schuur Hospital in Cape Town, South Africa, offers a PD-First policy as a result of haemodialysis (HD) restrictions and resource limitations. This study aimed to compare health-related quality of life (HRQOL) between $\mathrm{HD}$ and peritoneal dialysis (PD) patients, given the lack of autonomy in modality choice and the socio-economic challenges. This single-centre, cross-sectional study was performed between July 2015 and December 20I6. Demographic, socio-economic variables and perceptions of safety were collected. HRQOL was assessed using the Kidney Disease Quality of Life-Short Form (KDQOL-SFTM) version I.3. All data were compared between the two dialysis modalities; $77 \mathrm{HD}$ and $33 \mathrm{PD}$ patients were included in the study and there were no significant differences in demographics. Median age was 42.5 years (IQR: $32.4-48.6)$ and $57.3 \%$ were female. HD patients had less pain $(P=0.036)$, better emotional well-being $(P=0.020)$ and a better energy/fatigue score $(P=0.015)$. Both cohorts experienced role-limitations due to physical health with $P D$ being more affected overall $(P=0.05)$. The only significant symptom in the kidney domain was that PD patients experienced more shortness of breath $(\mathrm{P}<0.00 \mathrm{I})$. Patients in both groups had very poor socio-economic circumstances, and safety within their communities was a major concern. The patients in our dialysis service have very challenging social circumstances. Those on PD scored worse in four $\mathrm{HRQOL}$ domains, possibly due to a lack of autonomy in dialysis modality choice and less frequent contact with dialysis staff. Additional psychological and social support needs to be instituted to help improve our patients' well-being on PD.

Keywords: haemodialysis; peritoneal dialysis; South Africa; PD-First, health-related quality of life; HRQOL.

\section{BACKGROUND}

Although South Africa $(S A)$ is a middle-income country, it has the highest Gini coefficient in the world [I]. Not only is the distribution of wealth among the population grossly unequal, there is high unemployment (24.5$27.1 \%$ ) and poor access to formal housing and sanitation [2]. This is further complicated by gang violence and high crime rates [3]. Compounding these significant social stressors is a high burden of both communicable (human immunodeficiency virus (HIV) and tuberculosis (TB)) and non-communicable diseases [4]. Kidney failure is influenced by, and contributes to, this burden.

There are also competing priorities for health resources. HIV and TB currently overwhelm a predominantly public health care sector, which serves more than $80 \%$ of the population [5]. Despite the growing burden of chronic kidney disease (CKD) in SA, the number of patients able to access kidney replacement therapy (KRT) in the public sector is 68 per million population ( $\mathrm{pmp}$ ) compared to $798 \mathrm{pmp}$ in the private sector. Private dialysis numbers are on a par with many developed countries [5]. Due to severe resource constraints, national guidelines mandate that only patients who are transplantable can be accepted in most public sector dialysis programmes [6].

The Western Cape province has an estimated population of 6.36 million, with $74.8 \%$ (4.76 million) who access public health care [2]. Groote Schuur Hospital (GSH) is

Received 25 June 2020; accepted I October 2020; published 18 December 2020. 
one of five treatment centres for KRT in the public sector of the Western Cape in Cape Town. At the time of the study reported here, the main unit at GSH had the capacity to dialyse 148 patients, 98 on haemodialysis (HD) and 50 on peritoneal dialysis (PD). The unit institutes dialysis rationing, which is ethically endorsed and strictly adhered to. There is a PD-First policy. This is due both to limitations in HD slots and cost-saving measures. The PD-First programme ensures that all patients are started on PD, unless there is a compelling contraindication. Contraindications include significant lack of social amenities including lack of running water, lack of storage space for PD fluid or a medical contraindication. If PD fails, patients are able to be switched from PD to HD only if they remain transplantable. Patients that are not suitable for modality switch will remain on PD. Non-transplantable HD patients are not removed from the HD programme. At the time of the study reported here, our PD programme had only glucose containing fluid, with no access to icodextrin and limited access to automated PD (APD). APD is reserved for adolescents and patients who are employed [7].

Health-related quality of life (HRQOL) has been directly linked to mortality and hospitalisation rates [8]. Even with $K R T$, end-stage kidney disease (ESKD) has been shown to have a lower HRQOL than an age-matched population [9]. However, there is no consensus, even on meta-analysis, as to which modality (HD versus $P D$ ) is superior in terms of HRQOL [10].

In a PD-First programme, there is no choice for dialysis modality. Given the lack of patient autonomy, the need to understand our patients' quality of life $(\mathrm{QOL})$ and the associated challenges they face is essential. This study aimed to assess whether HRQOL differed between those on PD versus $H D$, in a resource-constrained setting serving a population with significantly poor social circumstances. The primary objective was to compare the HRQOL between dialysis modalities using the Kidney Disease Quality of Life-Short Form (KDQOL-SFTM) survey. Secondary objectives were to describe our cohort's socio-economic status and their perceived safety and security within their communities and homes.

\section{METHODS}

This cross-sectional study examined the HRQOL of patients on HD and PD at GSH. Ethics approval was granted by the University of Cape Town Human Research Ethics committee (reference number 480/20I5). Inclusion criteria consisted of all patients older than 18 years and established on a dialysis modality for at least 3 months. Exclusion criteria included age less than 18 years, patients not established on dialysis and those not granting consent.
Demographic data were collected including age, sex, ethnicity and marital status. Socio-economic information was collected using an adapted census questionnaire from Statistics South Africa (Stats SA). This included information regarding education, employment status, income, food security, living circumstances (for example, dwelling type, home occupants, access to water, electricity and sanitation), mode of transportation and distance to hospital. Patients thereafter completed a validated kidney health-related quality of life survey (KDQOL-SF version I.3) [I I]. This validated survey included 36 general health and 54 kidneyspecific questions, which were used to calculate scores for 8 general health domains and 11 kidney-specific domains. The general health domains included: physical and social functioning, role limitation due to physical and emotional problems, pain and health perceptions, emotional wellbeing and energy/fatigue levels. The kidney-specific domains included: symptoms, effects and burden of kidney disease, work status, cognitive function, quality of social interaction, sexual function, sleep, social support, dialysis staff encouragement and patient satisfaction [I I]. The questionnaire was verbally administered in the primary language of the patient (IsiXhosa, English or Afrikaans) by the research administrator and the primary investigator. The questionnaire was administered face-to-face in the clinic and on dialysis.

The KDQOL-SF scoring of the HRQOL was conducted according to the validated methods described in the original KDQOL-SF guidelines [ I I ]. Responses to the items of the KDQOL-SF were coded into a numeric value as per the scoring key. The coded values were then recoded between 0 and 100 and converted to a percentage, where $100 \%$ represented the most favourable quality of life. For example, patients with less pain had a higher HRQOL and thus a higher score in the pain domain. The second step averaged the scores of selected items, to form aggregated scores for the 8 general health domains and II kidneyspecific domains. Missing data were not taken into account when averaging the domain scores [ I I ]. Patients completed the survey only once and were not re-interviewed if they switched dialysis modality.

\section{Statistical analysis}

Demographic variables, socio-economic characteristics, SF36 health survey items, and ESKD targets were summarised using descriptive statistics. All SF-36 health survey items and ESKD target scores were presented as mean \pm standard deviation (SD). Skewed continuous variables were presented as median with interquartile range (IQR). Categorical variables were summarised by frequency with proportion. Variables were compared between dialysis groups using a two-sample t-test to compare ESKD target scores, while the Wilcoxon rank-sum test was used for non-normally distributed variables. Categorical variables 
were compared between dialysis groups using either the chi-squared test or Fisher's exact test, where appropriate. All analyses were performed using Stata/IC version 15 (StataCorp, College Station, TX, USA).

\section{RESULTS}

\section{Patient demographics, socio-economic and education}

The study population consisted of $77 \mathrm{HD}$ patients and 33 patients in the PD group. The surveys were performed between July 2015 and December 2016. A total of 154 patients were screened for study inclusion. There were 32 patients who did not complete the questionnaire (9 HD and 23 PD patients), as they missed their dedicated appointment. A further 12 patients were excluded from the study: 5 did not meet entry criteria, 5 did not grant consent and 2 returned incomplete forms. Of the PD cohort included in the study, 8 patients were not eligible for switch to HD due to loss of transplantability -3 had significant ischaemic heart disease, 2 had malignancies, and
3 demonstrated poor adherence to therapy. These patients remained on our PD programme. At the time of the study, there were 7 patients who were not transplantable on the HD programme.

Table I demonstrates the demographic, socio-economic and educational data of the two groups. There were no significant differences in demographics between the HD and PD cohorts. More patients were female ( $n=63,57 \%)$. Patients in the HD group were predominantly of African ethnicity (53\%), whereas the majority of those on PD were of mixed ancestry (61\%). The median age for the two groups was 42.5 years (IQR: 32.4-48.6 years). Most patients (62\%) were not married.

Less than half of the patients had completed secondary school (47\% on HD and $41 \%$ in the PD group). There were no significant differences between groups except for tertiary education (HD group, 39\% versus PD group, 19\%, $P=0.044)$. Employment was around one third in each group with only $33 \%$ and $29 \%$ in the HD and PD groups, respectively. Over $40 \%$ of patients in both groups relied on

Table I. Baseline demographics, education and socio-economic status of cohort.

\begin{tabular}{|c|c|c|c|c|c|}
\hline & & $\begin{array}{l}\text { Total cohort } \\
(\mathrm{N}=110)\end{array}$ & $\begin{array}{c}H D \\
(N=77)\end{array}$ & $\begin{array}{c}P D \\
(N=33)\end{array}$ & $P$ value \\
\hline \multicolumn{6}{|l|}{ Baseline demographic } \\
\hline Female & n (\%) & $63(57.2)$ & $44 / 77(57.1)$ & 19/33 (57.6) & 0.966 \\
\hline Population group* & n (\%) & $108(98.2)$ & & & 0.242 \\
\hline African & $n(\%)$ & $52(48.2)$ & 40/75 (53.3) & 12/33 (36.4) & \\
\hline Mixed ancestry & n (\%) & $52(48.2)$ & $32 / 75(42.7)$ & 20/33 (60.6) & \\
\hline White/Asian & $n(\%)$ & $4(3.7)$ & $3 / 75(4.0)$ & I/33 (3.0) & \\
\hline Age (years) & Median (IQR) & & $44.0(32.9-48.7)$ & $40.8(31.5-48.1)$ & 0.333 \\
\hline Marital status & & & & & 0.797 \\
\hline Single, widowed or divorced & n (\%) & $68(61.8)$ & $47 / 77(61.0)$ & $21 / 33(63.6)$ & \\
\hline Married & n (\%) & $42(38.1)$ & 30/77 (39.0) & $12 / 33(36.4)$ & \\
\hline \multicolumn{6}{|l|}{ Education } \\
\hline Primary & n (\%) & $8(7.34)$ & 6/77 (7.8\%) & $2 / 32(6.3 \%)$ & 0.567 \\
\hline Secondary & n (\%) & $49(44.9)$ & $36 / 77(46.8 \%)$ & I3/32 (40.6\%) & 0.355 \\
\hline Tertiary education* & $n(\%)$ & $35(32.7)$ & $29 / 75$ (38.7\%) & $6 / 32(18.8 \%)$ & 0.044 \\
\hline Currently studying* & $n(\%)$ & $5(4.67)$ & $2 / 75(2.7 \%)$ & $3 / 32(9.4 \%)$ & 0.157 \\
\hline \multicolumn{6}{|l|}{ Employment/ income } \\
\hline Employed currently & $n(\%)$ & $33(31.7)$ & $24 / 73(32.9 \%)$ & $9 / 31(29.0 \%)$ & 0.700 \\
\hline Disability grant/Pension & n (\%) & $47(42.7)$ & $33 / 77(42.9 \%)$ & | 4/33 (42.4\%) & 0.966 \\
\hline Household Income (ZAR) & Median (IQR) & & $3750(1600-6000)$ & $3750(1400-5400)$ & 0.546 \\
\hline $\begin{array}{l}\text { Hunger reported in the last year } \\
\text { (food security) }\end{array}$ & $n(\%)$ & $22(20 \%)$ & I 6/77 (20.8\%) & $6 / 33(18.2 \%)$ & 0.755 \\
\hline
\end{tabular}


Table 2. Living circumstances, transportation and safety.

\begin{tabular}{|c|c|c|c|c|c|}
\hline & & $\begin{array}{l}\text { Total cohort } \\
(\mathrm{N}=\mid 10)\end{array}$ & HD & PD & $P$ value \\
\hline Dwelling type & & & & & 0.964 \\
\hline House/flat/townhouse & n (\%) & $77(70)$ & $54 / 77$ (70.1\%) & 23/33 (69.7\%) & \\
\hline Shack/Back room & n (\%) & $33(30)$ & 23/77 (29.9\%) & 10/33 (30.3\%) & \\
\hline Home occupants & Mean (SD) & & $3.96(2.4)$ & $4.06(2.0)$ & 0.554 \\
\hline Occupant/Bedroom & Mean (SD) & & $2.06(1.2)$ & $1.77(1.0)$ & 0.231 \\
\hline \multicolumn{6}{|l|}{ Amenities } \\
\hline Water in house & n (\%) & $87(79.1)$ & $58 / 77$ (75.3\%) & 29/33 (87.9\%) & 0.107 \\
\hline Electricity in house & n (\%) & 105 (95.4) & 75/77 (97.4\%) & $30 / 33$ (90.9\%) & 0.158 \\
\hline Toilet in house" & $n(\%)$ & $74(81.3)$ & $50 / 62(80.7 \%)$ & $24 / 29(82.8 \%)$ & 0.528 \\
\hline Safety score ${ }^{* *}$ & $\operatorname{Avg}(\mathrm{SD} ; \mathrm{Cl})$ & & $47.9(33.0 ; 40.4-55.4)$ & $52.4(31.5 ; 41.2-63.6)$ & 0.508 \\
\hline Mode of transportation & & & & & 0.205 \\
\hline Public & n (\%) & $87(79.9)$ & 63/77 (81.8\%) & 24/33 (72.7\%) & \\
\hline Private & n (\%) & $23(20.9)$ & | 4/77 (| $8.2 \%)$ & 9/33 (27.3\%) & \\
\hline Distance from unit $(\mathrm{km})$ & Median (IQR) & & $18(13-23)$ & $20(13-25)$ & 0.121 \\
\hline
\end{tabular}

"Denominator varies due to missing values. "The safety score was generated from $1-10$ and multiplied by 10 , where $0=$ completely unsafe and $100=$ completely safe. Abbreviations: HD, haemodialysis; PD peritoneal dialysis; SD, standard deviation; Avg, average; Cl, confidence interval; km, kilometre; IQR, inter-quartile range.

disability grants or pensions as a source of income. The average income for our patients overall was low, with a median income of R3 750 per month, equivalent to US\$200. Around one fifth of patients reported hunger at some point over the previous year.

\section{Living circumstances, transport and safety}

Table 2 describes the living circumstances of the cohort. Thirty percent of patients lived in an informal dwelling or a room detached from the main abode. In the HD group, $75 \%$ had access to tap water in their house, compared to $88 \%$ in the PD group. Flushing toilets were not present in 19\% (17) of patient homes. Most patients used public transportation to access dialysis; $82 \%$ in the HD group and $73 \%$ in the PD group. On average, patients lived $18-20 \mathrm{~km}$ from the dialysis unit.

The patients' perception of safety within their home environment and communities was rated on a scale from 0- 100 ( 100 equated to complete safety and 0 to a feeling of being dangerously unsafe). The study population felt generally unsafe in their home environments and performing their daily activities within their neighbourhoods. HD patients scored an average of $47.9 \pm 33.0$ and the PD group scored $52.4 \pm 31.5$.

\section{Health-related quality of life}

Table 3 describes the results of the general health domains of the KDQOL-SF. Both groups experienced similar limi- tations due to their physical health, although patients on $P D$ were found to be more limited $(P=0.05)$. There was a significant difference in pain between the groups. The HD group had a higher composite score for pain (77.5) than the PD group (65.3) ( $P=0.036)$. Despite PD patients recording a worse pain score, there was no difference in pain-limiting activity. The emotional well-being was significantly higher in the HD group (72.9) compared to the PD group (62.5) ( $P=0.020)$, with the HD group reporting to be less nervous, calmer and happier. Additionally, the HD group had significantly better energy/fatigue scores than the PD group (59.4 vs 48.0, $\mathrm{P}=0.015$ ).

Table 4 reports the ESKD-specific domains. There was no significant difference in overall symptom score between the cohorts (78.2 vs 71.7 , respectively; $P=0.068$ ). Only shortness of breath was significantly different between the groups (HD $84.4 \pm 23.3$ vs PD 62.I \pm 34.3; $P<0.001$ ). Both groups experienced a high burden of kidney disease symptoms and sleep disturbance.

On subgroup analysis of the PD cohort ( $n=33), 9$ patients died during the study period, 6 were transplanted and 13 were switched to HD. Nine patients (27\%) had no peritonitis and 24 (72\%) had one or more peritonitis events. A subgroup analysis of the PD cohort was performed. It compared the symptom burden of pain, shortness of breath, energy/fatigue and emotional well-being between the overall PD cohort and I) patients who experienced peritonitis, 2) those who experienced technique failure and 


\begin{tabular}{|c|c|c|c|}
\hline & $\begin{array}{c}\text { HD } \\
N(78) \\
\text { Mean (SD) }\end{array}$ & $\begin{array}{c}\text { PD } \\
N(33) \\
\text { Mean (SD) }\end{array}$ & $P$ value \\
\hline Physical functioning: ${ }^{*} \mathrm{n}=76 ; 33$ & $66.9(23.2)$ & $63.2(26.0)$ & 0.471 \\
\hline Role-limitations due to physical health & $44.3(38.8)$ & $28.8(34.3)$ & 0.050 \\
\hline Less time & $52.0(50.9)$ & $42.4(50.2)$ & 0.365 \\
\hline Do less & $32.9(47.3)$ & I $8.2(39.2)$ & 0.120 \\
\hline Limit type of work " $n=75 ; 33$ & $44.0(50.0)$ & $27.3(45.2)$ & 0.102 \\
\hline Difficulty & $46.1(50.2)$ & $27.3(45.2)$ & 0.067 \\
\hline Pain & $77.5(25.7)$ & $65.3(31.7)$ & 0.036 \\
\hline Amount & $76.1(27.0)$ & $61.3(33.7)$ & 0.017 \\
\hline Limiting activity & $78.9(28.4)$ & $68.9(32.5)$ & 0.110 \\
\hline General health & $51.4(22.4)$ & $49.5(21.5)$ & 0.683 \\
\hline Emotional well-being & $72.9(20.7)$ & $62.5(22.1)$ & 0.020 \\
\hline Nervous " $n=76 ; 33$ & $77.6(28.7)$ & $62.4(38.3)$ & 0.024 \\
\hline Down & $72.0(31.0)$ & $64.2(29.9)$ & 0.230 \\
\hline Calm ${ }^{n} \mathrm{n}=75 ; 33$ & $67.2(31.3)$ & $53.3(32.7)$ & 0.039 \\
\hline Blue ${ }^{*} n=76 ; 33$ & $71.6(26.2)$ & $69.7(32.1)$ & 0.748 \\
\hline Happy & $77.4(25.8)$ & $63.0(35.0)$ & 0.018 \\
\hline Role limitations due to emotions & $55.0(46.4)$ & $41.4(44.1)$ & 0.157 \\
\hline Social functioning & $68.3(30.4)$ & $59.5(32.1)$ & 0.171 \\
\hline Energy/fatigue & $59.4(20.3)$ & $48.0(25.6)$ & 0.015 \\
\hline Vibrant & $59.0(31.1)$ & $54.5(30.5)$ & 0.494 \\
\hline Amount ${ }^{*} n=76 ; 33$ & $50.5(31.9)$ & $37.6(33.8)$ & 0.059 \\
\hline Worn-out "n = 76;33 & $69.5(26.2)$ & $55.2(5.8)$ & 0.019 \\
\hline Tired & $57.9(26.7)$ & $44.9(36.1)$ & 0.038 \\
\hline
\end{tabular}

"Denominator varies due to missing values. Abbreviations: $\mathrm{HD}$, haemodialysis; PD peritoneal dialysis; $\mathrm{SD}$, standard deviation.

3) those patients who were not eligible for a modality switch. When these symptoms were analysed, there were no significant differences in symptom burden between the overall cohort and these groups. (Supplementary Table I)

\section{DISCUSSION}

This cross-sectional study was performed in a single-centre, public sector hospital in SA and compared HRQOL between HD and PD patients. The centre offers a PD-First programme due to resource restrictions. All patients are started on PD unless a contraindication exists. Patients that are not transplantable are not eligible for modality switch and remain on their current mode of dialysis. Therefore, this study describes the symptom burden and HRQOL of patients on both HD and PD, and contains patients in both cohorts who were being palliated on their modality.
Understanding patient symptom burden and HRQOL in these circumstances is particularly pertinent, as patients lacked the autonomy to select their preferred modality.

This study highlighted the significant challenges that our dialysis cohort faces, particularly with regard to their poor socio-economic circumstances. A large proportion of our dialysis patients rely on disability grants for income, have food insecurity and live in informal housing. The concern within the cohorts regarding personal safety within their communities and homes was profound. These challenges were likely to affect patients' $\mathrm{QOL}$ and their experience on dialysis. Although there were no significant differences in symptoms overall, the study demonstrated that HD patients reported less pain, shortness of breath, fatigue and better energy scores with an overall improvement in emotional well-being. The degree of kidney disease burden 
Table 4. End-stage kidney disease-targeted Items.

\begin{tabular}{|c|c|c|c|}
\hline & $\begin{array}{c}\text { HD } \\
N(77) \\
\text { Mean (SD) }\end{array}$ & $\begin{array}{c}\text { PD } \\
N(33) \\
\text { Mean (SD) }\end{array}$ & $P$ value \\
\hline Symptoms/problems & $78.2(17.1)$ & $71.7(16.8)$ & 0.068 \\
\hline Soreness & $77.3(28.7)$ & $72.7(28.9)$ & 0.449 \\
\hline Chest pain & $89.5(21.3)$ & $80.3(29.8)$ & 0.072 \\
\hline Cramps & $68.4(32.8)$ & $70.5(30.3)$ & 0.761 \\
\hline Pruritus & $66.9(36.4)$ & $53.8(4 \mid .5)$ & 0.100 \\
\hline Dry skin & $65.6(39.1)$ & $53.0(39.4)$ & 0.127 \\
\hline Shortness of breath & $84.4(23.3)$ & $62.1(34.3)$ & $<0.001$ \\
\hline Faintness & $81.2(28.7)$ & $80.3(27.1)$ & 0.883 \\
\hline Loss of appetite & $83.1(24.9)$ & $72.7(37.7)$ & 0.090 \\
\hline Feeling drained & $74.0(31.7)$ & $69.7(33.5)$ & 0.523 \\
\hline Paresthesia & $82.8(30.2)$ & $73.4(36.4)$ & 0.169 \\
\hline Nausea & $77.6(29.9)$ & $78.8(30.7)$ & 0.854 \\
\hline Effects of kidney disease & $64.1(23.9)$ & $65.5(22.4)$ & 0.776 \\
\hline Burden of kidney disease & $41.4(30.6)$ & $44.3(32.0)$ & 0.651 \\
\hline Work status & $33.8(45.5)$ & $33.3(42.7)$ & 0.963 \\
\hline Cognitive function & $79.8(21.9)$ & $78.4(16.9)$ & 0.737 \\
\hline Quality of social interaction & $78.8(19.7)$ & $73.3(22.6)$ & 0.206 \\
\hline Sexual function ${ }^{*}$ & $83.6(23.6)$ & $80.6(19.9)$ & 0.727 \\
\hline Sleep & $67.0(21.1)$ & $58.9(21.9)$ & 0.069 \\
\hline Social support & $81.2(25.4)$ & $76.8(31.2)$ & 0.439 \\
\hline Dialysis staff encouragement & $88.5(18.2)$ & $89.8(18.6)$ & 0.734 \\
\hline Patient satisfaction & $65.4(26.6)$ & $72.7(24.2)$ & 0.179 \\
\hline
\end{tabular}

" $n=32$ for HD group and 9 for PD group. Abbreviations: HD, haemodialysis; PD peritoneal dialysis; SD, standard deviation.

and emotional impact of the illness was marked in both cohorts. Peritonitis, experiencing technique failure and not being eligible for modality switch did not affect symptom burden.

Patients on dialysis commonly experience pain. The prevalence has been estimated to range between 40-60\% $[12,13]$. In one study, more than $80 \%$ rated their experience of pain as moderate or severe [14]. Pain is therefore an important contributor to QOL $[13,14]$. Pain is also associated with adverse outcomes such as impaired sleep, decreased mood, adherence and withdrawal from dialysis therapy $[12,14]$. There are conflicting data on whether there is a significant difference in the frequency of pain syndromes between different dialysis modalities [15-17]. There are studies that demonstrate that patients on HD have lower pain scores than those on PD; however, the pain did not appear to affect or limit activities [18,19]. Our study revealed pain to be a common symptom in both cohorts, although less pain was experienced in those on HD.

Despite the influence of pain on QOL in dialysis patients, there is a paucity of data on the underlying causes. The aetiology is multi-factorial, although the most common cause has been described as being musculoskeletal in nature [12,20]. A comprehensive pain assessment and an attempt to identify the root cause of pain is essential to assist in improving $\mathrm{QOL}$ in dialysis patients.

In the ESKD-specific domains both cohorts scored similarly. However, on further analysis, PD patients experienced significantly more "shortness of breath". Patients took the questionnaire when they attended the PD clinic. It is possible they were interviewed outside of their scheduled visit and during a period of fluid overload. In a previously reported outcome study from our PD unit, the commonest cause of death was fluid overload [7]. Unfortunately, due to resource constraints, we have limited access to automated 
peritoneal dialysis [APD] and icodextrin, which may contribute to the high degree of fluid overload seen.

Fatigue is a common symptom during all stages of CKD, reported in 49-100\% of patients [21]. Although not examined in this study, when haemoglobin levels were previously examined between our HD and PD cohorts no significant differences were seen [I5]. In our study, HD patients scored better in the domain of "energy/fatigue", they specifically reported feeling less worn-out and tired; this is similar to studies performed in Mexico, SA and Turkey [22-24]. It has been reported that patients with higher energy/fatigue scores also show better pain scores [17], which might explain the greater degree of pain experienced in our PD patients. We did not examine dialysis vintage as part of the study; it is likely that our HD cohort had a longer vintage on dialysis. Longer vintage has been linked to less pain in previous studies [25].

The HD patients also had better emotional well-being scores, specifically in the areas of nervousness, calmness and happiness. This is similar to a study in Turkey, where they found that PD patients were more likely to have a depressive mood [24]. Brazil, a country with a similar gross domestic product to SA, reported similar findings. Here they demonstrated that HD patients had better emotional well-being than PD patients when a QOL survey was performed [26]. However, numerous studies, including two from SA, showed no difference or improved emotional wellness on PD [15,23,27], which has known advantages of flexibility and autonomy that have been linked to less interruption to lifestyle.

The reasons for the possible improved feeling of well-being on HD may be attributed to the additional regular emotional support provided by fellow patients on HD and the regular contact with nursing staff. Furthermore, HD patients are also likely to have been on their modality longer.

\section{Socio-economic status}

The socio-economic status of our patients is very poor, and this creates an extremely challenging environment in which to live with a chronic illness and benefit from KRT. This may have profound effects on QOL. No differences were demonstrated in living circumstances between the $\mathrm{HD}$ and PD patients, despite lack of running water and sanitation being a contraindication for PD in our selection criteria. Our study compared the socio-economic circumstances of our dialysis population with the Western Cape province and South African census data. (Supplementary Table 2) [2]. It confirmed that our dialysis cohort faced more social challenges than the average population. The unemployment rate was higher, a much lower household income was reported, and there was a higher percentage of hunger described with more patients residing in informal dwellings. Access to running water and flushing toilets was also more limited. This is a concern as a lack of running water places PD patients at an increased risk of peritonitis. All these issues highlight the challenges of performing PD in our setting.

Education was similarly low within both cohorts for primary and secondary school completion. Those on HD had a higher rate of completing tertiary education (38\%) than those on PD (18\%), P $=0.044$. Even though level of education has been shown not to affect HRQOL in PD patients in Brazil [28], it is associated with an increased risk for first peritonitis events independent of socio-economic factors [29].

More than $60 \%$ of our patients felt unsafe walking around their neighbourhood at night. This is not surprising, given that Cape Town has one of the highest reported rates of violent crime and murder ( $1647 / 100000$ population and $63 / 100000$ population, respectively) [3]. There is an extremely high murder rate compared to the global average of only 6/100 000 population [30]. The lack of security could be contributing to the high levels of insomnia, anxiety and low energy experienced by the entire cohort.

\section{Limitations}

This study has several limitations. First, the sample of PD patients was much lower than the HD. This was due to a fixed number of patients that were able to access chronic dialysis due to resource constraints. We used a convenience sampling method, which resulted in unequal groups, and we did not ensure the study was sufficiently powered to detect differences between groups. Therefore, the interpretation of significance testing was limited in this study. These considerations will be taken into account in future research. Second, biochemical measures of dialysis adequacy and haemoglobin, which could affect QOL, were not reported. However, we know from previously published data from our centre that adequacy and outcomes of our PD cohort are comparable to other, larger PD programmes, in high-income countries [7]. Third, dialysis vintage was not recorded for this study. Fourth, the causes of pain on the two modalities were not evaluated. Lastly, we did not compare rates of depression on the two modalities.

\section{CONCLUSIONS}

In our setting, a PD-First programme is essential if we are to offer KRT to patients who would otherwise not have access. In this socio-economic setting, patients on PD 
reported lower HRQOL than patients on HD in four categories related to symptoms of ESKD and psychological well-being. This may in part relate to our patients' lack of autonomy in choosing their dialysis modality and it may in part relate to the inability of some patients failing on PD to transition to HD. This study has highlighted the necessity to provide additional support to our PD patients. Possible interventions to improve $\mathrm{QOL}$ could include ongoing repeated educational interventions, patient support groups and social worker assistance as required. Furthermore, a more intensive pre-dialysis education programme may reduce patient anxiety and improve emotional well-being, especially in PD patients for whom there is less frequent contact with the nursing staff.

\section{Supplementary materials}

Appendix I includes Table SI, which is a comparison of the symptoms within the PD patient cohort, and Table S2, which is a comparison of socio-demographic variables between the study cohort and populations of the City of Cape Town, the Western Cape province and South Africa.

\section{REFERENCES}

I. GINI index World Bank Estimates: https://data.worldbank.org/ indicator/SI.POV.GINI (accessed 29 April 2020).

2. Statistics South Africa http://www.statssa.gov.za/ (accessed I5 Oct 2019).

3. South African Police Service (SAPS). Annual Crime Report 2015/20 | 6. http://saps.gov.za (accessed 31 Aug 2019).

4. Mayosi BM, Lawn JE, van Niekerk A, Bradshaw D, Abdool Karim SS, Coovadia HM, et al. Health in South Africa: changes and challenges since 2009. Lancet. 20 I2; 380(9858):2029-2043.

5. Davids MR, Jardine T, Marais N, Zunza M, Jacobs JC, Sebastian S. South African Renal Registry Annual Report 2017. Afr J Nephrol. 2019; 22(I):60-7|.

6. Moosa MR, Wearne N. Invited commentary: Should we be rationing dialysis in South Africa in the 21 st century? Periton Dial Int. 2018; 38(2):84-88.

7. Davidson B, Crombie K, Manning K, Rayner B, Wearne N. Outcomes and challenges of a PD-First program, a South African perspective. Periton Dial Int. 2018; 38(3): 179-186.

8. Pei G, Zhang Z, Peng J, Liu L, Zhang C, Yu C, et al. Renal involvement and early prognosis in patients with COVID-19 pneumonia. J Am Soc Nephrol. 2020; 3 I (6):I I 57- I 65.

9. Hamilton AJ, Caskey FJ, Casula A, Ben-Shlomo Y, Inward CD. Psychosocial health and lifestyle behaviors in young adults receiving renal replacement therapy compared to the general population: Findings from the SPEAK study. Am J Kidney Dis. 2019;73(2): 194-205.

10. Queeley GL, Campbell ES. Comparing treatment modalities for end-stage renal disease: A meta-analysis. Am Health Drug Benefits. 2018;1 I (3):1 18-127.

II. Hays RD, Kallich, J. D., Mapes, D. L., Coons, S. J., Amin, N. \& Carter, W. B. Kidney Disease Quality of Life-Short Form (KDQOL-SFTM), Version 1.3: A Manual for Use and Scoring. RAND. 1995; P-7994.

12. Davison SN. Pain in hemodialysis patients: prevalence, cause, severity, and management. Am J Kidney Dis. 2003; 42(6): 1239- 1247.
2017 update on pain management in patients with chronic kidney disease. Clin Kidney J. 20 I7; I0(5):688-697.

14. Weisbord SD, editor. Patient-centered dialysis care: Depression, pain, and quality of life. Seminars in Dialysis; 2016: Wiley Online Library.

15. Okpechi IG, Nthite T, Swanepoel CR. Health-related quality of life in patients on hemodialysis and peritoneal dialysis. Saudi J Kidney Dis Transplantation. 20 I3;24(3):5 I9.

16. Mau L-W, Chiu H-C, Chang P-Y, Hwang S-C, Hwang S-J. Healthrelated quality of life of Taiwanese dialysis patients: Effects of dialysis modality. Kaohsiung J Med Sci. 2008;24(9):453-460.

17. Zazzeroni L, Pasquinelli G, Nanni E, Cremonini V, Rubbi I. Comparison of quality of life in patients undergoing hemodialysis and peritoneal dialysis: a systematic review and meta-analysis. Kidney Blood Pressure Res. 2017;42(4):717-727.

18. dos Santos Grincenkov FR, Fernandes N, Chaoubah A, da Silva Fernandes N, Bastos K, Lopes AA, et al. Longitudinal changes in health-related quality of life scores in Brazilian incident peritoneal dialysis patients (BRAZPD): socio-economic status not a barrier. Periton Dial Int. 20 I 3;33(6):687-696.

19. Atapour A, Nasr S, Boroujeni AM, Taheri D, Dolatkhah S. A comparison of the quality of life of the patients undergoing hemodialysis versus peritoneal dialysis and its correlation to the quality of dialysis. Saudi J Kidney Dis Transplant. 2016;27(2):270.

20. Pham P-CT, Toscano E, Pham P-MT, Pham P-AT, Pham SV, Pham P-TT. Pain management in patients with chronic kidney disease. NDT plus. 2009;2(2): 1 1 1-118.

21. Almutary H, Bonner A, Douglas C. Symptom burden in chronic kidney disease: a review of recent literature. J Renal Care. 20। 3;39(3): I 40- 150.

22. Reynaga-Ornelas L, Baldwin CM, Arcoleo K, Quan SF. Impact of sleep and dialysis mode on quality of life in a Mexican population. Southw J Pulmon Crit Care. 2019;18(5):I22.

23. Tannor EK, Archer E, Kapembwa K, Van Schalkwyk SC, Davids MR. Quality of life in patients on chronic dialysis in South Africa: a comparative mixed methods study. BMC Nephrol. 20 17;18(1):4.

24. Turkmen K, Yazici R, Solak Y, Guney I, Altintepe L, Yeksan M, et al. Health-related quality of life, sleep quality, and depression in peritoneal dialysis and hemodialysıs patıents. Hemodialysis Int. 2012; 1 6(2):198-206.

25. Schmalz G, Dietl M, Vasko R, Müller GA, Rothermund L, Keller F, et al. Dialysis vintage time has the strongest correlation to psychosocial pattern of oral health-related quality of life-a multicentre cross-sectional study. Medicina Oral, Patología Oral y Cirugía Bucal. 2018;23(6):e698.

26. Gonçalves FA, Dalosso IF, Borba JMC, Bucaneve J, Valerio NMP, Okamoto CT, et al. Quality of life in chronic renal patients on hemodialysis or peritoneal dialysis: a comparative study in a referral service of Curitiba-PR. J Bras Nefrol. 20 I5;37(4):467-474.

27. Zhang AH, Cheng LT, Zhu N, Sun LH, Wang T. Comparison of quality of life and causes of hospitalization between hemodialysis and peritoneal dialysis patients in China. Health Qual Life Outcomes. 2007:5( I):49.

28. dos Santos Grincenkov FR, Fernandes N, Chaoubah A, da Silva Fernandes N, Bastos K, Lopes AA, et al. Longitudinal changes in health-related quality of life scores in Brazilian incident peritoneal dialysis patients (BRAZPD): socio-economic status not a barrier. Perit Dial Int. 2013;33(6):687-696.

29. Martin LC, Caramori JC, Fernandes N, Divino-Filho JC, Pecoits-Filho R, Barretti P, et al. Geographic and educational factors and risk of the first peritonitis episode in Brazilian Peritoneal Dialysis study (BRAZPD) patients. Clin J Am Soc Nephrol. 20 I 1;6(8): 1944- 195 I.

30. Global study on homicide executive summary. https://www.unodc. org/documents/data. Accessed February 2019. 
APPENDIX I: SUPPLEMENTARY TABLES

Table SI. Comparison of symptoms within the PD patient cohort.

\begin{tabular}{|lcccccccccc|}
\hline & \multicolumn{3}{c}{ Peritonitis } & & \multicolumn{2}{c}{ PD patients not eligible for switch } & & \multicolumn{2}{c|}{ Switched to HD } \\
\hline & Yes & No & P value & Yes & No & P value & Yes & No & P value \\
\hline Pain & $63.8 \pm 6.2$ & $69.5 \pm 12.2$ & 0.653 & $65.3 \pm 13.2$ & $65.3 \pm 6.1$ & 0.999 & $77.9 \pm 7.8$ & $58.1 \pm 7.1$ & 0.084 \\
Energy & $45.6 \pm 5.7$ & $54.4 \pm 6.1$ & 0.386 & $38.7 \pm 9.3$ & $51.0 \pm 5.0$ & 0.245 & $55.8 \pm 6.9$ & $43.6 \pm 5.7$ & 0.189 \\
Emotional wellness & $60.3 \pm 4.6$ & $68.4 \pm 6.9$ & 0.357 & $64.0 \pm 8.8$ & $62.1 \pm 4.4$ & 0.834 & $67.3 \pm 4.6$ & $59.8 \pm 5.4$ & 0.356 \\
SOB & $57.3 \pm 7.9$ & $75.0 \pm 4.2$ & 0.191 & $65.6 \pm 12.4$ & $61.0 \pm 6.9$ & 0.746 & $68.8 \pm 8.8$ & $58.3 \pm 8.1$ & 0.41 \\
\hline
\end{tabular}

Table S2. Comparison of socio-demographic data between study cohort and populations of the City of Cape Town, the Western Cape province, and South Africa.

\begin{tabular}{|c|c|c|c|c|}
\hline & Dialysis cohort (\%) & $\begin{array}{l}\text { City of Cape Town } \\
(n=4005016)(\%)\end{array}$ & $\begin{array}{c}\text { Western Cape } \\
(n=6 \quad 279730)(\%)\end{array}$ & $\begin{array}{c}\text { South Africa } \\
(n=55653654)(\%)\end{array}$ \\
\hline Female & 57 & 51.6 & 50.7 & - \\
\hline \multicolumn{5}{|l|}{ Population group } \\
\hline African & 48 & 42.6 & 35.7 & 80.4 \\
\hline Mixed & 48 & 39.9 & 47.5 & 7.2 \\
\hline White/Asian & 4 & 17.6 & 16.8 & 12.4 \\
\hline Married (pop. aged >|8) & 38 & 41.1 & 40.2 & 30.7 \\
\hline \multicolumn{5}{|l|}{ Education (pop. age 20+) } \\
\hline Primary school & 7.3 & 4.2 & 5.1 & - \\
\hline Secondary school & 45 & 35.0 & 33.8 & - \\
\hline Tertiary & 32.7 & 14.8 & 12.7 & - \\
\hline Employed & 31.7 & - & - & $42.5-44.3$ \\
\hline Household income per month (ZAR) & 3750 & - & 18580 & $1|5| 4$ \\
\hline Reporting hunger (\%) & 21.8 & 12.7 & 13.2 & 19.9 \\
\hline \multicolumn{5}{|l|}{ Dwelling (\%) } \\
\hline Formal & 70 & 81.6 & 82.4 & 79.2 \\
\hline Informal & 30 & 17.6 & 16.6 & 13.0 \\
\hline Traditional/Other & - & 0.7 & 1.0 & 7.8 \\
\hline Home occupants & & 3.2 & 3.2 & - \\
\hline Water (\%) & 79.1 & 93.7 & 93.2 & 84.5 \\
\hline Electricity (\%) & 95.4 & 97.8 & 97 & - \\
\hline Flushing toilet (\%) & 81.3 & 92.8 & 93.4 & 63.4 \\
\hline
\end{tabular}

Abbreviations: pop, population; ZAR, South African rand.

Data sources: 201 I Census Municipal Report. Western Cape report no. 03-01-49 (accessed 19 November 20 I7); Statistics South Africa http://www.statssa.gov.za/ (Accessed I5 Oct 2019). 